\title{
Effect of Fly Ash Particles on the Mechanical Properties of Zn-22\%Al Alloy via Stir Casting Method
}

\author{
Maniram Singh Gurjar $^{1}$, Satender Dehiya ${ }^{1}$, Manoj Sharma ${ }^{2}$, N.C. Upadhyay ${ }^{1}$ \\ ${ }_{1}$ Metallurgical and Materials Engineering Department, MNIT Jaipur, India. \\ ${ }^{2}$ Materials Science and Engineering Department, IIT Gandhinagar, India.
}

\begin{abstract}
In the present investigation, a Zn-22\%4l alloy is used as the matrix material and fly ash as the filler material. The composite is produced using powder metallurgy techniques. The fly ash is added in $2 \%, 4 \%$ and $6 \%$ by wt $\%$ to the sintering metal. The composite is tested for hardness, density and tensile strength test. Microstructure examination is done using a high resolution optical microscope to obtain the distribution of fly ash in the Zn-Al matrix. Test results indicate that as fly ash content is increased, there is a considerable increase in hardness and tensile strength but decrease in density.
\end{abstract}

Keywords: Metal Matrix Composites, Fly Ash.

\section{Introduction}

Metal Matrix composites (MMCs) are advanced engineered materials resulting from a combination of two or more materials (one of which is a metal) in which tailored properties are achieved. As current functional materials reach their performance limits, designers are looking to MMCs to provide the extra strength, stiffness, and higher temperature capabilities required for advanced applications. Compared with unreinforced metal alloys, MMCs generally offer the following advantages: higher specific strength, stiffness, weight reduction, better resistance to wear and impact damage, a lower thermal coefficient of expansion (CTEs), tailorable thermal conductivity, and better vibration damping [1,2]. Potential application areas for these types of materials include aerospace, defense, automotive, sporting goods, and marine. It is separated from the exhaust gases of coal-fired thermal power plants using electrostatic or mechanical precipitators and is generally finer than Portland cement, with a relative density that varies from 1.3 to 4.8 depending on the mineralogy of the coal burnt [3]. It consists mainly of small glassy spheres of varying sizes (ranging from less than $1 \mathrm{~mm}$ to more than $100 \mathrm{~mm}$ ) $[3,5]$. The constituents of fly ash are based on the mineral content of the coals used. The major constituents are oxides and mixed metal oxides of silicon, aluminium, iron, and calcium there by making them ceramic in nature. The disposal of fly ash from coal-fired power stations causes significant economic and environmental problems [6]. The fly ash production in NTPC alone is expected to be about 72 million tons by 2012 and about 100 million tons by 2017 [7]. A relatively small percent of fly ash is consumed worldwide. Although the utilization level varies from a minimum of $3 \%$ to a maximum of $57 \%$, the world average only amounts to about $16 \%$ of the total ash [3]. Canada utilizes about $25 \%$ of its fly ash production in cement, concrete, mining applications and road construction while the remaining amount is disposed of in landfills, ash dams and lagoons at a significant cost to the utility companies and their customers [8]. This unproductive use of land and lagoons and the associated long-term financial burden of maintenance and environmental pollution have led to the realization that alternative uses for fly ash as a valueadded product beyond the aforementioned uses are needed.

The physical and chemical properties of fly ash make it a useful construction and industrial material, especially in cement manufacturing, concrete, liquid waste stabilization, and hydraulic mine backfill [35]. Utilization of fly ash in producing novel materials, waste management, recovery of metals and agriculture are the new areas that will expand the positive reuse of this abundant material, thereby helping to reduce the environmental and economic impacts of its disposal. Currently, researches are been carried out on the use of fly ash as a filler and reinforcement materials in MMCs [8]. Prior studies show that fly ash can be used in forming inexpensive $\mathrm{Zn}-\mathrm{Al}$ alloys MMCs with improved mechanical properties that can compete favorably in terms of strength and hardness with other available composites. This provides a high value-added use of fly ash in producing composites with improved material properties, such as wear resistance and low density, and at a reduced cost [9]. These composites can find useful applications in machine parts, sporting goods, electronic packaging, automotive and aerospace components. These will, as a result, help in reducing the discharge of greenhouse gases thereby fulfilling some of the key objectives of the Kyoto Protocol. 


\section{Experimental Procedure}

Commercially pure EC grade aluminium powder (400 grams) and pure zinc ( 950 grams) were melted in a resistance heated furnace. Melt temperature was raised to $700^{\circ} \mathrm{C}$ and it was degassed by hexa-chloro ethane tablets to make $\mathrm{Al}-22 \% \mathrm{Zn}$ master alloy. Clay graphite crucible is used for casting purpose. Fly ash supplied by JK Tyre, Morena was used in this investigation and it is preheated to a temperature of $600{ }^{\circ} \mathrm{C}$ for two hours to remove the moisture.

Table 1. Composition of Fly Ash Used.

\begin{tabular}{|l|l|}
\hline Compound & Weight \% \\
\hline $\mathrm{SiO}_{2}$ & 61.01 \\
\hline $\mathrm{Al}_{2} \mathrm{O}_{3}$ & 28.03 \\
\hline $\mathrm{Fe}_{2} \mathrm{O}_{3}$ & 8.40 \\
\hline $\mathrm{MgO}$ & 1.05 \\
\hline $\mathrm{SO}_{3}$ & 0.40 \\
\hline LOI (Loss of Ignition) & 0.71 \\
\hline OTHER & 0.40 \\
\hline
\end{tabular}

Fly ash $2 \%, 4 \%, 6 \%$ by weight percentage was added to the Al-22\%Zn melt maintained at a temperature ranging between $670{ }^{\circ} \mathrm{C}$ to $700{ }^{\circ} \mathrm{C}$ to cast three samples of varying composition. Fly ash particles were added to the melt at the time of vortex formation in the melt due to constant stirring. The size, distribution and shape of powder particle were evaluated using optical microscopy.

\section{Results and Discussion}

\subsection{Hardness}

Hardness of finally casted samples of fly ash with Al-22\%Zn was determined using Vickers hardness testing machine and following results were obtained.

Table 2. Vickers Hardness of Various Compositions of Composite.

\begin{tabular}{|l|c|c|c|c|}
\hline \multirow{2}{*}{ Composition (by weight \%) } & \multicolumn{4}{|c|}{ Vickers Hardness (HV) } \\
\cline { 2 - 5 } & $\mathbf{1}^{\text {st }}$ Reading & $\mathbf{2}^{\text {nd }}$ Reading & $\mathbf{3}^{\text {rd }}$ Reading & Average \\
\hline $\mathrm{Zn}-22 \% \mathrm{Al}$ & 110.14 & 112.53 & 111.20 & 111.29 \\
\hline $\mathrm{Zn}-22 \% \mathrm{Al}+2 \%$ fly ash & 116.34 & 115.19 & 116.52 & 116.01 \\
\hline $\mathrm{Zn}-22 \% \mathrm{Al}+4 \%$ fly ash & 120.79 & 122.15 & 121.55 & 121.83 \\
\hline $\mathrm{Zn}-22 \% \mathrm{Al}+6 \%$ fly ash & 125.46 & 126.84 & 126.52 & 126.27 \\
\hline
\end{tabular}

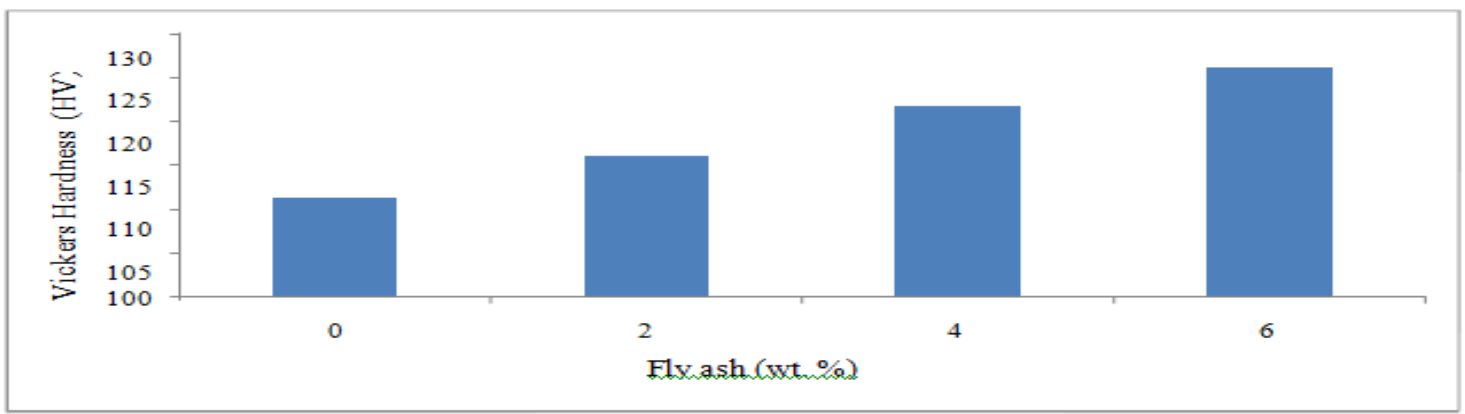

Fig. 1 Graph showing the effect of increasing weight $\%$ of fly ash on Vickers hardness of the metal matrix composite.

\subsection{Tensile Strength}

Tensile test was performed by tensile tensometer on the ASTM E8/E8M standard sized tensile specimen of various compositions with $2 \mathrm{~mm} / \mathrm{s}$ strain rate and following results were obtained. 
Table 3. Tensile strength of various compositions of composite.

\begin{tabular}{|l|c|c|c|c|}
\hline \multirow{2}{*}{ Composition (by weight \%) } & \multicolumn{4}{|c|}{ Tensile Strength (MPa) } \\
\cline { 2 - 5 } & $\mathbf{1}^{\text {st }}$ Reading & $\mathbf{2}^{\text {nd }}$ Reading & $\mathbf{3}^{\text {rd }}$ Reading & Average \\
\hline Zn-22\%Al & 217 & 223 & 220 & 220 \\
\hline Zn-22\%Al + 2\% fly ash & 240 & 241 & 245 & 242 \\
\hline Zn-22\%Al + 4\% fly ash & 268 & 275 & 273 & 272 \\
\hline Zn-22\%Al + 6\% fly ash & 298 & 306 & 308 & 303 \\
\hline
\end{tabular}

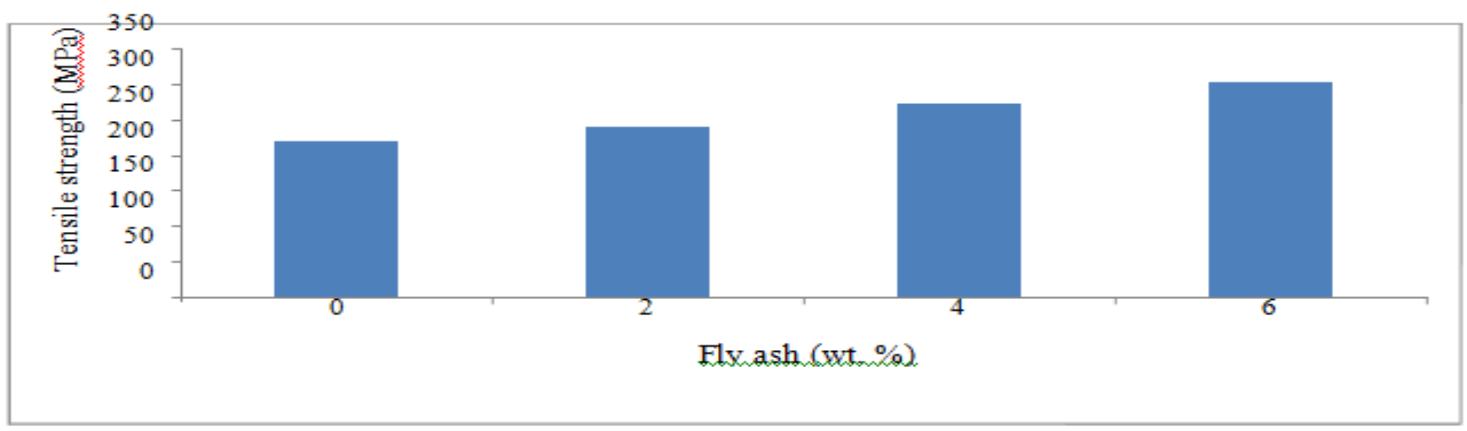

Fig. 2 Graph showing the effect of increasing weight $\%$ of fly ash on tensile strength of the $\mathrm{Zn}-22 \% \mathrm{Al}$ alloys.

\subsection{Density Testing}

Density test was performed using Archimedes principle on the samples of various composition and following results were obtained.

Table 4. Density of various compositions of composite.

\begin{tabular}{|c|c|c|c|}
\hline \multirow[b]{2}{*}{ Composition (by weight \%) } & \multicolumn{3}{|c|}{ Density $\left(\mathrm{gm} / \mathrm{cm}^{3}\right)$} \\
\hline & $1^{\text {st }}$ reading & $2^{\text {nd }}$ reading & Average \\
\hline $\mathrm{Zn}-22 \% \mathrm{Al}$ & 6.118 & 6.136 & 6.127 \\
\hline $\mathrm{Zn}-22 \% \mathrm{Al}+2 \%$ fly ash & 5.982 & 6.076 & 6.029 \\
\hline $\mathrm{Zn}-22 \% \mathrm{Al}+4 \%$ fly ash & 6.032 & 5.902 & 5.967 \\
\hline $\mathrm{Zn}-22 \% \mathrm{Al}+6 \%$ fly ash & 5.864 & 5.918 & 5.891 \\
\hline
\end{tabular}

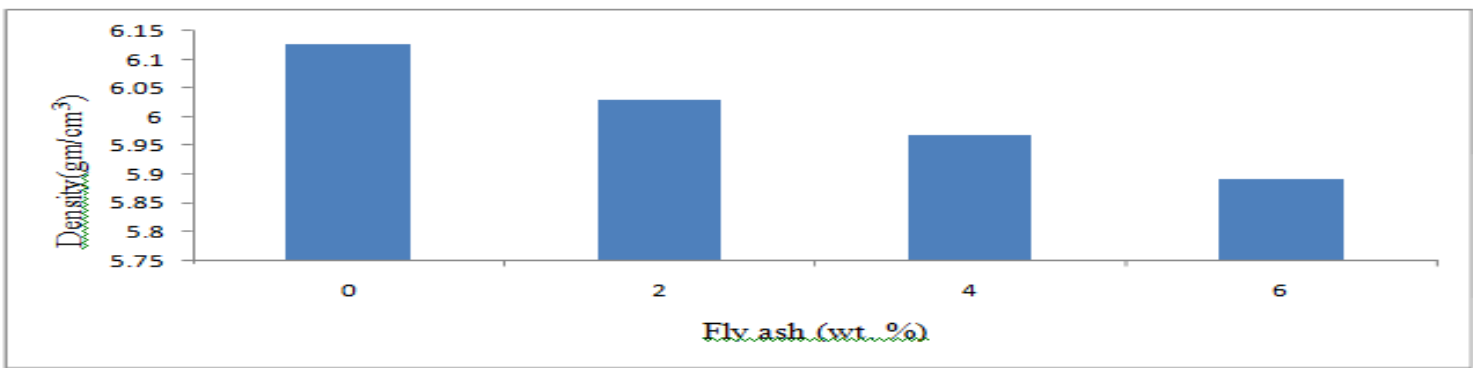

Fig. 3 Graph showing the effect of increasing wt $\%$ of fly ash on density of the metal matrix composite. 


\section{Optical Microscope Image Analysis}

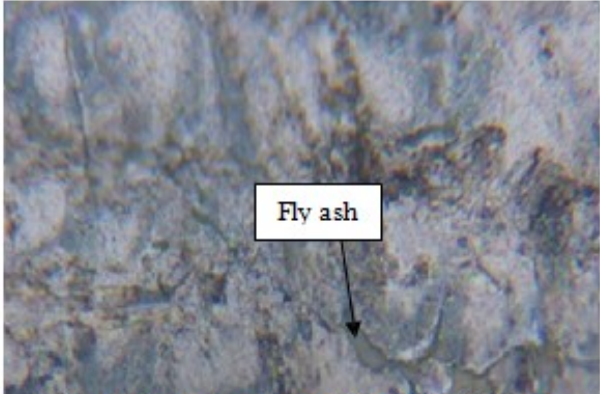

Fig. 4 Microstructure of $\mathrm{Zn}-22 \% \mathrm{Al}$ alloy.

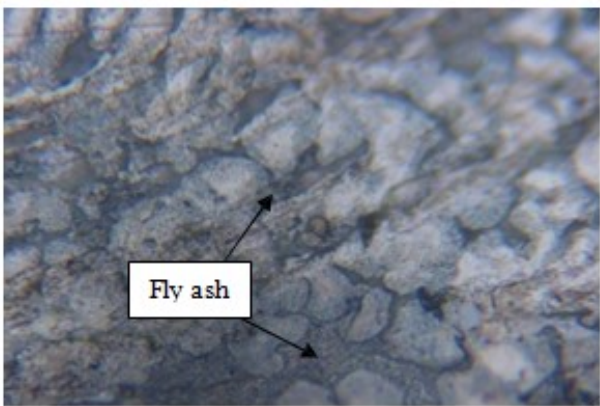

Fig. 6 Microstructure of $\mathrm{Zn}-22 \% \mathrm{Al}$ alloy with $4 \%$ fly ash

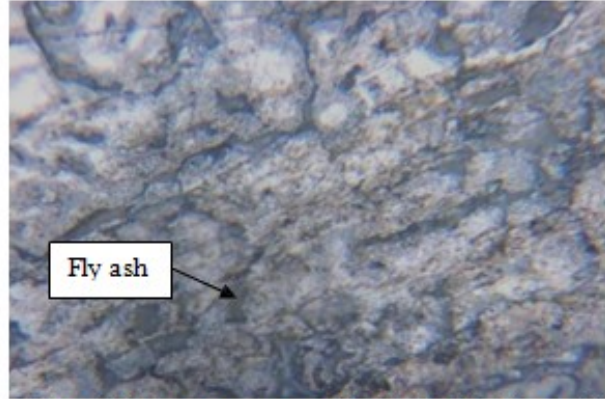

Fig. 5 Microstructure of $\mathrm{Zn}-22 \% \mathrm{Al}$ alloy with $2 \%$ fly ash.

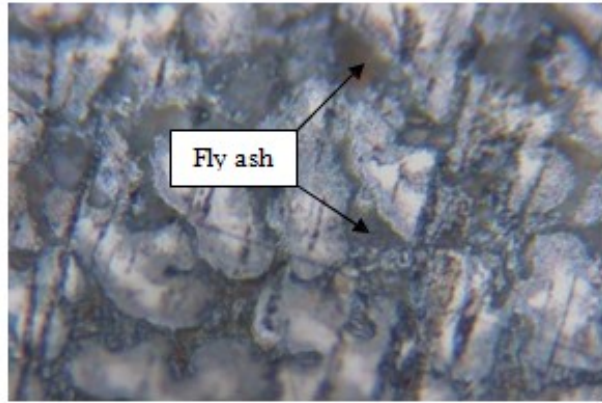

Fig. 7 Microstructure of $\mathrm{Zn}-22 \% \mathrm{Al}$ alloy with $6 \%$ fly ash.

\section{Conclusions}

From the present work, it is concluded that fly ash can be used for the production of composites and thus turn industrial waste into industrial wealth. This can also solve the problem of storage and disposal of fly ash to quite an extent.

“ Hardness of $\mathrm{Zn}-22 \% \mathrm{Al}$ alloy is increased from $111 \mathrm{HV}$ to $126 \mathrm{HV}$ with addition of fly ash.

“ Tensile strength of Zn-22\%Al alloy is increased from $220 \mathrm{MPa}$ to $303 \mathrm{MPa}$ with addition of fly ash

“ Density of $\mathrm{Zn}-22 \% \mathrm{Al}$ alloy is reduced from $6.127 \mathrm{~g} / \mathrm{cm}^{3}$ to $5.891 \mathrm{~g} / \mathrm{cm}^{3}$ with addition of fly ash.

\section{References}

[1] R. Subramanian,G. Prabhu "Some Studies on Aluminium - Fly Ash Composites Fabricated by Casting Method" European Journal of Scientific Research, Vol.63 No.2 (2011), 204-218

[2] M. Ebisawa, T. Hara, T. Hayashi and H. Ushio, "Production Processes of Metal Matrix Composite (MMC) Engine Block", SAE Transaction, Vol. 100,(1991), 826-838.

[3] R. C. Joshi and R. P. Lohtia "Fly Ash in Concrete Production, Properties and Uses", Gordon and Breach Science Publishers, Amsterdam, (1997), 1-47.

[4] V. M. Malhotra and A. A. Ramezanianpour, "Fly Ash in Concrete", 2nd edn, CANMET, Natural Resource of Canada, Ottawa, (1994), 1-18. [5] R. A. Helmuth, "Fly Ash in Cement and Concrete", Portland Cement Association, Skokie, Illinois, (1987), 1-64.

[6] R. S. Iyer and J. A. Scott, "Power Station Fly Ash - A Review of Value-Added Utilization Outside of the Construction Industry", Resources, Conservation, and Recycling., Vol. 31, (2001),217-228.

[7] http://www.ntpc.co.in/images/content/environment/books/2010-11/Fly-Ash-for-Cement Concrete.pdf

[8] P. K. Rohatgi, "Low-Cost, Fly Ash Containing Aluminium Matrix Composites", JOM, Vol. 29, (1994), 55-59.

[9] J. Bijen, "Fly Ash Aggregates", in Fly Ash, Silica Fume, Slag \& Other Mineral By-Products in Concrete, 2nd Ed., V. M. Malhotra (ed.), American Concrete Institute, Detroit, (1983). 